Article

\title{
Is It Possible to Manage the Product Recovery Processes in an ERP? Analysis of Functional Needs
}

\author{
Raul Oltra-Badenes *, Hermenegildo Gil-Gomez, Vicente Guerola-Navarro $₫$ and Pau Vicedo \\ Department of Business Organization, Universitat Politècnica de València, 46022 Valencia, Spain \\ * Correspondence: rauloltra@doe.upv.es
}

Received: 27 June 2019; Accepted: 9 August 2019; Published: 13 August 2019

\begin{abstract}
In today's business environment, different factors make product return and product recovery increasingly more important in order to recover value and increase the company's profitability. In such an environment, where sustainability concerns and awareness of environmental responsibility in industrial production has considerably grown, reverse logistics (RL) becomes more relevant and, thus, its correct management using suitable information systems (IS) is fundamental. Nevertheless, today's IS in general, and in Enterprise Resources Planning (ERP) in particular, are developed based on conventional logistic processes that do not contemplate the specific characteristics of RL. The main objective of this work is to analyze the functional requirements of an IS to manage product recovery processes that serve as a guide to develop a suitable ERP for RL. The research methodology has been conducted with a qualitative approach, through which the main specific requirements that an IS must meet to manage RL have been stablished, and a data model for the development of solutions to the requirements identified in an ERP system has been proposed. For the development in the ERP it is recommended to start with the requirement of RBOM (Reverse Bill Of Materials) management, since it is the most complex development and has a greater relationship with the rest.
\end{abstract}

Keywords: reverse logistics; ERP; product recovery; value recovery; information systems

\section{Introduction}

Nowadays, economic, marketing and legislative guidelines lead companies to collect and recover their products after they have been used [1]. This situation means that reverse logistics (RL) is becoming more important, as well as a very relevant and crucial process for the global sustainability trend because as well as the economic profits that can be made, its inclusion in companies' processes and its management can reduce the environmental damage caused by markets, especially manufacturing companies [2]. This is why it has drawn the attention of a growing number of researchers, as clearly reflected by the many publications found on the subject, particularly those considering case studies in several industries, especially waste management [1]. In this scenario, the use of RL is highly recommended in sectors that include the return of after-sales and post-consumer goods, including industrial waste. This entails all activities associated with the collection, recovery and elimination of used products.

RL management entails a series of given processes that differ from those in traditional logistics management. Specific RL processes mean that the information systems (ISs) followed for their management must include a series of specific requirements. However, current IS are neither developed for nor adapted to the specific requirements of RL. In fact, lack of IS adapted to RL requirements is one of the main internal barriers for RL being practiced in organizations [3,4].

In today's business environment, where information is a key factor of business competitiveness, IS should be able to manage all a company's processes, including characteristic RL processes. The integrated management of all processes by means of an IS allows a company's management to 
have the necessary information available to make the most suitable decisions at all times, which will increase its productivity and improve its results.

ERP includes all a company's processes in a single system [5], is essential for efficiently managing the company and is fundamental in an Industry 4.0 environment [6], where implementing ERP is the first phase of the transformation into a smart factory [7]. Effectively managing a company can be achieved, provided that its organizational structure and operations are properly outlined from an ERP system perspective [8].

The first step to be able to develop a suitable IS to manage RL is to know the specific problems that such management produces. The main objective of this article is to present the specific requirements that an IS must meet to manage RL, as well as establishing a data model that can be used for the development of solutions to the requirements identified in an ERP system. This work has two main contributions: a contribution to theory, and a contribution to practice. The analysis of the specific RL processes and the existing problem for their management in an ERP system represents the main contribution to theory. The literature allowed us to conclude that an information system to manage RL properly is not yet available, although highly relevant. On the other hand, the data model proposed represents the main contribution to practice, as it can be used to design and develop specific solutions in particular ERP systems, adapting the data model proposed to their particular processes and databases.

This work is arranged as follows: First, in the next section, the research methodology, including a literature review, is presented. In Section 3, fundamental concepts of RL are revised and the basic differences between RL and direct logistics (DL) are examined. Section 4 analyzes the implications of integrating RL processes into ERP, and after that, Section 5 presents the development requirements to adapt ERP to RL management and a data model proposal. Finally, the conclusions drawn from the work are presented.

\section{Research Methodology}

The research methodology was conducted following a qualitative approach [9]. Aligned with the design-science methodology [10], an extensive literature review was conducted as the first step of the methodology. The literature review was done searching in the Web Of Science (WOS), a Web technology-based platform that includes the references of the main scientific publications of any discipline of knowledge. The following keywords were identified: "reverse logistic", "product recovery", "ERP", "Recycling" and "Software Requirement". As the list of articles retrieved when searching for each of the keywords in an independent way was very vast, a more elaborated search was conducted. In order to find information which combined more than one of these topics, we used Boolean operators such as OR, AND, NOT.

Queries used for the search were the following ("Reverse logistic *" AND "ERP *" 14 result), (Reverse Logistic *" AND "Information System *"; 84 results), ("Reverse Logistic *" AND "Software Requirement"; 0 results), ("Product Recovery" AND "ERP *"; 1 result), ("Product Recovery" AND "Information System *"; 20 results), ("Product Recovery" AND "Software Requirement *"; 0 results), (Recycling" AND "ERP *"; 75), ("Recycling" AND "Information System *"; 356") and ("Recycling" AND "Software requirement *"; 2). A careful selection of the results was made. First, filtering by research areas related, excluding those clearly out of scope (i.e., neurosciences neurology, immunology, geology, geography, nursing, etc.). Second, reading the titles and abstracts of the articles in order to select the papers related with the research objective. The selected papers were reviewed in detail. Some interesting works were found, regarding the information and information systems as important factors to fulfill the goals of a sustainable supply chain [11-13].

Other works present a conceptual model identifying the key requirements for measuring enterprise sustainability [14] or an analysis of differences between the manufacturing and service sectors in the matter of developing a sustainable environmental supply chain [15]. 
An integrated model for reverse logistics management is proposed in [16], considering elements such as ERP, WEB services and other ICT elements (RFID, QR or bar Codes). Nevertheless, it does not delve into the characteristic processes of the RL and its specific information needs.

Other research line is followed in [17], where the concept of ABSC (Activity-Based Standard Costing) is proposed. This concept is integrated into ERP and MES (Manufacturing Execution Systems) for achieving efficient production management in digital environments, and a case study is conducted in a steel factory, which adapts the complicated recycling of steel-scrap material. Another case study is presented in [18], where the authors propose a methodological framework for flexible design of remanufacturing systems to improve the economic performance based on remanufacturing laptop computers for the Cambodian market.

More recent, and more related to our research, is the reverse collaboration framework (RCF) presented in [19]. The RCF proposed connects tools, techniques, systems and RL processes. Applying the RCF to a consumer electronics business, the authors demonstrate that integrating ERP and WMS (Warehouse Management Systems) to execute the RL processes can increase performance and productivity of RL operations. However, to execute these processes in an adequate manner, an IS adapted to RL is needed; it means an ERP system, able to carry out all the RL detailed activities, integrating all the department and processes requirements (financial, logistics, etc.). Some ERP systems have functionality or modules to manage specific activities, as the Return Material Authorization (RMA) module of SAP. This module can manage the return of products with different options, and for the case study in a servicing organization in the health care sector is very useful [20]. Nevertheless, although some RL activities can be managed in an ERP in isolation [20], there are no appropriate ERP's to the RL management in an integrated way [3-5,19,21-28].

Regarding the management of waste and recycling processes, no papers have been found that identify the specific needs of their management information systems, and less specific in ERP. However, there are papers in the literature indicating the importance of managing waste properly, a problem that grows day by day, particularly in emerging countries. Especially worrying is the case of E-waste, or waste generated from electrical and electronic equipment (WEEE), considered as one of the fastest growing waste categories [29]. Due to different factors (i.e., significant advances in the electronics and information and communications technology industries, changes in consumption patterns and consumers' lifestyles, short product life spans due to technological innovations, and economic development) the generation of WEEE has increased dramatically compared to other solid waste streams. Consequently, WEEE is gaining primary importance in waste management domain [30]. In this case, there are articles in the literature identifying some basic processes that should be included in proper e-waste management [31], and they and their requirements have been considered in our work. However, there are no studies identifying the need of an IS to manage these recycling processes properly or the particular requirements they have.

Therefore, the literature review found no works having analyzed the implications that RL management presents in IS, despite one of the most serious identified problems that companies face in RL management being scarcity of IS capable of suitably managing their processes [21]. In [4], 35 barriers are identified for implementing RL based on a thorough literature review. After analyzing them, it was concluded that lack of suitable information technologies and IS for RL is one of the five most important barriers. Lack of suitable IS for RL is identified in [3] as one of the main barriers to adopt it. More recently [19] indicates that no suitable IS exist to manage product recovery processes and to meet the involved socio-environmental obligations.

For that reason, our work focuses on this research line by analyzing the requirements that RL entails in IS as a first step to develop suitable ERP to manage RL.

In order to achieve the main objective of this work, which is, to present the specific requirements that an IS must meet to manage the RL and propose a data model that can be used to develop solutions to the requirements identified in an ERP system, a requirements engineering methodology is also followed. Obviously, in that methodology, the first phase must be the "Requirements elicitation" [32]. 
Requirements elicitation is the process of discovering the requirements for a system through consultation with stakeholders, system documents, domain knowledge and market studies. For this activity, there are some recommended techniques, depending of the existing scenario [32]. The techniques used to elicit the requirements in this case were: document study and semi-structured interviews with experts. Semi-structured interviews are exploratory and allow the interviewer to vary the list of questions depending on the profile and expertise of the interviewee and add relevant questions which were not initially determined [20]. As the persons to be interviewed were from different departments and with different backgrounds, this interview method was considered to be the most beneficial for this work, as it combines structured questions in order to obtain the required information, and, in the same time, it grants a degree of flexibility during the interview while it gives the opportunity to further explore specific topics.

Therefore, in this work, a qualitative direct focus research procedure has been used, such as an in-depth interview with experts [9]. In exploratory research, the experience, creativity and ingenuity of the researcher play a very important role [33]. The information collected was carefully examined and completed with the literature review. Following the steps presented in the literature review section, information from scientific articles and specialized books was combined with internal company memoranda, publications in the press and direct observation of the management of different business organizations.

Subsequently, this information was shared with a panel of experts, with different profiles, all of them related to RL and ERP systems: ERP implementation consultants, company department managers (logistics, financial and information systems), software developers, database analysts and specialists in information technology integration.

The information generated was analyzed, and the requirements identified were grouped depending on the business process to which they belong. With all this knowledge, an analysis of the specific RL processes and their management in an ERP system could be done. After that, the analysis of requirement and development of a data model for RL processes management was proposed.

\section{Research Background}

In today's modern market, characterized by dynamism and competitiveness, it is increasingly common for companies to face the challenge of how to recover products or materials from customers, for either value recovery reasons or as after-sales services. Consequently, in the 70's, a research line appears on product recovery or reverse distribution focusing on product returns and operational processes of managing end-of-life (EOL) products [20]. This reverse process is called "Reverse Logistics" encompasses all the logistic activities from used products which are no longer required by the users to products again usable in a market [34].

$\mathrm{RL}$, also called "retrologistics" or "recovery and recycling logistics", has several accepted definitions. One of the most accepted in the literature can be found in [21] and states that RL consists in the process of planning, implementing, and controlling the efficient flow of raw materials, in-process inventory, finished goods and related information from the point of consumption to the point of origin for the purpose of recapturing value or proper disposal. Other authors include also manufacturing activities in the Reverse Logistics definitions, such as recycling or recovery of EOL products [35].

From the above definitions, we can deduce that, in a way, the reviewed authors agree that the RL concept is a process that moves goods from their typical final destination to recover value and to ensure their correct disposal, even though companies view this purpose merely as a marketing tool. In this way, RL becomes an important sector with activities that fall within logistics. Some of these activities only have ecological connotations, such as recovering and recycling products to, thus, avoid harming the natural environment. Others seek to improve not only production and forecast processes, but also benefits. Some operations that can be framed within RL include: Processes to return excess stock, customer returns, obsolete products, excess stock of seasonally demanded products, etc., 
and the activities of withdrawing, classifying, reconditioning and resending products to a point of sale or to other secondary markets.

\subsection{Product Recovery}

By means of RL, when a product is returned to a company, regardless of it being returned during a product guarantee period or when a product's shelf life ends, the company has several ways of managing it to recover part of its value. It has been distinguished the following recovery forms in accordance with the point of reentry in the value chain: Reuse, repair, restoration, remanufacture, cannibalization, recycling, energy recovery, and garbage dumps [36]. More recently, It was also identified remanufacturing, repair and recycling as product recovery options, and later, some different types of reuse have been defined [37,38].

The option of "reuse" concerns recovering a product and conferring it a new use. For instance, reusing computer material used in offices with obsolete specifications for teaching tasks. In general terms, reuse is the form that least impacts the environment (except when technologies that use lots of energy or are highly polluting are resorted to). Reuse is also limited to certain product types. Its generalized application is difficult, mainly due to rapid product obsolescence at a time of marked technological change. There is the option of recovering all or part of the components through different ways: Repair, restoration, remanufacture and cannibalization. The three first options imply reconditioning and improving product quality. They differ given their processing complexity insofar as repair implies less effort than restoration which, in turn, involves less effort than remanufacturing. "Cannibalization" is based on recovering certain components or parts for them to be incorporated into other products. Recycling is one of the most popularly understood ways of giving a second life to materials: Recovering materials to be used again as raw material in another manufacturing process. Recycling materials generally involves certain loss because materials are mixed and some of their properties degrade. To a certain extent, a consensus has been reached on recycling being one of the most promising options for the future to solve the problem of what to do with products when their shelf life ends. The option "energy recovery" consists on extracting the energy content of certain product parts by combustion. This option is not very recommendable nowadays because, in fact, it does not make the best of the source of raw materials that waste is assumed to be. Furthermore, their combustion causes a new source of polluting emissions that must be strictly controlled. As well, the final option is "garbage dumps". Although this is not actually a valid recovery alternative, it should be the last resource used to dispose products when their shelf life ends, not only because attempts must be made to not reject materials that can be reused or recycled, but also because of the growing requirements, difficulties and costs that garbage dumps involve.

Obviously, the feasibility of a company carrying out these product recovery options is subject to many considerations: technical feasibility, product quality, existence of infrastructures, the costs involved, environmental consequences, etc. It is also necessary to suitably manage information to be able to duly run the related processes.

\subsection{Differences between RL and DL Management}

Recovered products management, a characteristic of RL, does not take place in DL. Consequently, RL management differs from the traditional logistic management concept and it is not possible to transfer traditional models and concepts from DL to RL [39], rather new concepts and models need to be established to manage them.

For years, concepts and models have been developed to manage DL. Many specialists in logistics attempt to transfer these DL models and concepts to RL. However, RL is not necessarily "a symmetrical direct logistics picture" [40]. So, it is necessary to know in-depth the differences between the two fields to be able to apply conventional logistic concepts to RL that bear in mind the differences between both.

There are some usually accepted differences between both types of logistics [39]. DL allows the company to make relatively more simple forecasts than RL does. DL involves usually transport from 
one to many (instead of the "transport from many to one" from RL). DL concerns uniform product quality and uniform product packaging, being not usual with RL. Other usual features from DL are: Clearly defined destiny/route, standard channel, clear product availability options, relatively uniform prices, the importance of rapid deliveries is acknowledged, direct distribution costs are clearly controlled by accounting systems, consistent inventory management, manageable product shelf life, direct negotiation among the involved parties, perfectly well-known marketing methods, product follow-up information is available in real time. On the other hand, RL brings usually different featuring properties: undefined destiny/route, channel led by exceptions, unclearly defined availability options, prices depend on many factors, rapid deliveries are not usually considered a priority, RL costs are much less visible, inconsistent inventory management, Much more complex product shelf life management, negotiation is more complex given additional considerations, marketing is much more complex due to different factors, the process is much less visible. Finally, with DL the traditional production process consists in assembling and manufacturing, while with RL the production process consists in disassembly and remanufacturing. These differences mean that RL management implies a series of specific characteristics that do not take place in DL management. Therefore, RL has been the object of many research works in recent years [19]. Literature reviews in this domain are found which classify research works according to the point of view from which RL is investigated [32,41] and more recently [2].

\subsection{RL Management in ERP Systems}

Nowadays, the reference solution for companies' IS worldwide is ERP [6]. Therefore, the present study assumes that analyzing RL requirements in IS must be done from the ERP viewpoint. ERP is an IS that brings about dramatic changes in organizations by changing both the IS environment and the corporate business process in general by also allowing organizations to maximize their performance [42]. However, IS capable of managing characteristic RL processes are lacking by including ERP in these systems. ERP systems are company management software devised and developed as generic management systems that apply to any company's different processes [43]. If analyzed in detail, several organizations that might belong to different industrial sectors have distinct business processes [22]. Accordingly, they also have different IS requirements either of the products, processes, markets or, specifically, the management type in the sector. To face this circumstance, ERP suppliers have adopted a "verticalization" strategy, which appears to be one of the most obvious trends in company software markets [5]. Verticalization can be defined as "the adjustment, modification or extension of a general ERP solution to specific business processes in certain business sectors" [23].

Thus, a vertical ERP solution would include all those differential characteristics needed to manage some particular processes. In this way, an ERP solution adapted to RL could be considered a vertical solution because it involves being adapted to a series of specific processes. However, after analyzing different ERPs (SAP, Microsoft, SAGE, Infor, Oracle, CCS Agresso, Odoo, OpenBravo and Compiere), and after reviewing and studying the specialized literature [5,22-28], it was found that ERP solutions that specifically implement RL are lacking. This review also stressed that works studying how to deal with RL management in an ERP system are also scarce. Therefore, developing an ERP solution that is capable of managing RL is necessary.

\section{Specific RL Processes and Their Management in ERP}

This section analyzes management processes that are characteristic of RL to identify and examine the specific requirements appearing from them that must be included in an ERP solution adapted to RL.

\subsection{Disassembly and Remanufacturing Management}

One of the basic matters considered to develop a suitable ERP for RL is efficient product return management. Effective product returns and safe product relocation/disposal can reduce environmental 
harm and economic loss. Therefore, remanufacturing products have potential environmental benefits [38] and help industry to fall in line with sustainability objectives [2].

Of the possible recovered products management options, in the "remanufacturing" option one of the most important phases of the process is disassembly [44] in which returned products, also called "cores", are disassembled to give way to a series of given parts to be inspected and tested at a later date. The parts that meet quality standards are stored to be reused. The parts with a slight fault can be mended, while those rejected given the bad state, they were in are scrapped. Some examples of such can be found in managing electrical appliances, photographic cameras, photocopiers, laptops or servers $[37,38,44]$.

According to [44], three fundamental requirements can be found to adapt IS to disassembly management:

1. Suitably registering cores (returned products before disassembling) in the inventory of the IS;

2. Scheduling disassembly. This requirement is not considered in current IS;

3. The joint management of manufacturing premises for the final assembly and for "remanufacturing", which are often shared.

In order to show a clear example of recovery and classification processes for returned products, the case of returning refrigerators presented in [37] is used. The list of production materials of the Refrigerators [37] is detailed below in Figure 1, and the particularities of management that its components imply is explained below. This example also shows the consistent recycling, disassembling, and reuse of its components or of the complete product, as well as the impact that these processes have on the business management that should reflect and manage an ERP system.

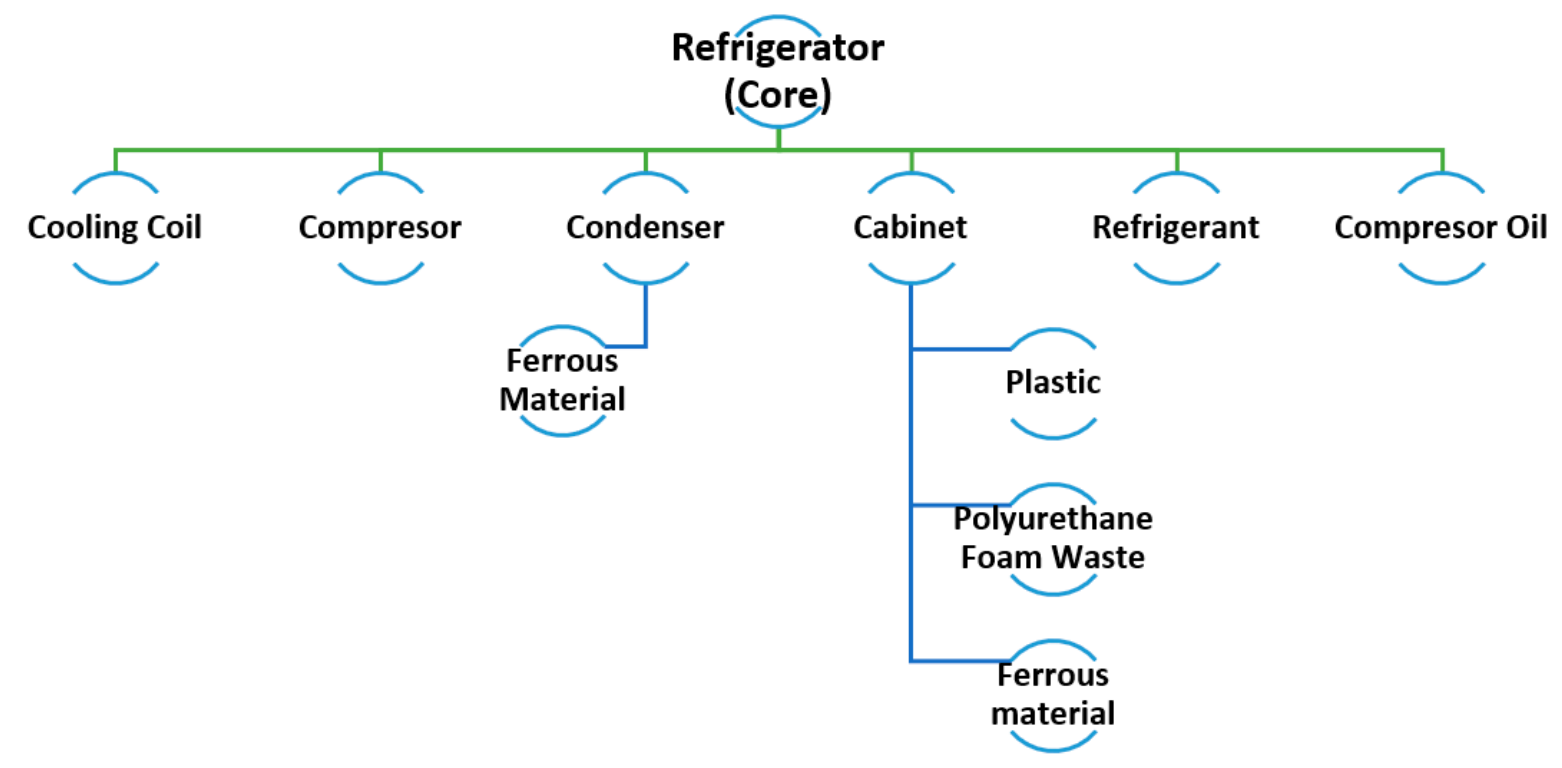

Figure 1. Product structure of a refrigerator (adapted from [16]).

The recovery process designed for refrigerators in [37] shows reverse supply chain which collects, and processes used refrigerators. It was evaluated and graded the returned products based on remaining useful life (RUL), and also studied the sensitivity of the design decisions with respect to variations of different input parameter values [37]. Figure 1 shows the structure of the refrigerator, reduced to the level required for RL study.

In a society like the present one, increasingly aware of environmental risks, it is not acceptable to throw electronic, structural, chemical and gaseous components in an uncontrolled way into landfills or deposits that do not treat the waste. That is why this particular case (the refrigerators) is paradigmatic of the use or treatment that must be done on them for an effective and efficient recovery of components 
that is respectful with the environment and at the same time that is in accordance with an efficient policy of use of resources and return on investment.

The network described in [37] to recycle used refrigerators includes different activities, such as the collection of products (cores), dismantling, remanufacturing, recycling and repair, among others.

The products are collected and classified into different categories, according to their RUL. Therefore, the status of the core (the refrigerator in this case) must be identified and registered. Moreover, the core must follow a different process depending on its status. For example, high RUL refrigerators can be remanufactured, so they must be sent to remanufacturing centers. After the core disassembly, the different elements of the product structure of a refrigerator (Figure 1) must be treated differently due to its characteristics. In addition, depending on the status of in each particular unit, the process to be followed by each component may also vary.

For example, in the case of polyurethane foam, the presence of chlorofluorocarbon makes the recycling of the product extremely complicated, and the preferred option is to treat it chemically before sending it to a landfill. The oil in most refrigerated systems is usually contaminated, which makes it dangerous for the environment to send it to a landfill directly. For this reason, in order for the refrigerant gases to be reused, a recovery process is necessary (heating the oil, volatilizing the refrigerant gases and recognizing the residual oil).

As for plastic parts, most of them are made of plastic such as ABS (acrylonitrile butadiene styrene), polypropylene and polystyrene that are recyclable. Pieces such as drawers, shelves and boxes for vegetables can break and melt directly into pellets. The cabinet, including the internal liners, are also made of plastic that is recyclable. The cabinet is powered by a four stage separation machine (pneumatic, magnetic, eddy current and specific gravity) to recover recyclable plastic. Finally, and again from [37], the ferrous materials of the condenser and body parts are recycled directly. The refrigerant and the cooling coil are reused. The defective compressor is repaired and sold in the secondary market.

The recovery process followed for refrigerators, in which the cited requirements are observed, is described in [37]. Returned refrigerators (cores before disassembly) must be properly registered and included as stock. It is necessary to bear in mind that they do not enter via the purchases or production process, but via a "Return" process. Their destination might differ depending on the state they are in (reuse, repair, disassembly, scrapped, etc.). Then a process different than the "typical" warehouse entry one must be followed. The core that arrives (returned cores) must be identified, along with any information about its origin, the state it is in, etc. According to these data, the refrigerator (and its disassembled components) must follow different processes.

As for scheduling disassembly, It can be mentioned an option to avoid this limitation: the possibility of including negative requirements in relation to components in the bill of bills of materials (referred to as BOM (Bill Of Materials) henceforth) [44]. This implies scheduling an inventory entry by means of a negative use. That is, " -1 unit" of a component is used, so 1 unit of the component actually enters the inventory. So, in the refrigerators example, we assume that its BOM is that indicated in Figure 1 (which is a simplified example).

When one refrigerator is manufactured, the needed components reflected in Figure 1 will be used of those stored in the warehouse. However, if the negative requirements are used, when manufacturing "-1 refrigerator", a "negative use" of its components will take place, which means an entry in the inventory of certain units of each component.

This solution to manage disassembly, which is mentioned in [44] is not feasible because not all the components have to be recovered, nor do they have to follow the same process. Perhaps one unit of component $\mathrm{X}$ must be rejected. In this case, the reverse BOM (negative) is no longer correct, and costs management would be unsuitable. Thus, it would be a production order that gives way to several products from one only, and it would be necessary to distribute the costs among all the obtained products. This is not feasible in today's ERPs.

There is another added difficulty, since some components such as the Refrigerant or Compressor Oil, when manufactured " -1 unit" of Refrigerator, will not always return to stock "-X units" of these 
gases or oils. In the Recovery process, they can probably lose part of the initial load that was used to manufacture the Refrigerator that has now returned to warehouse. That is why in the BOM it is necessary to consider the presence of losses that can invalidate the use of the initial BOM of the assembly process as inventory management tools during the process of disassembly.

What all this means is that the disassembly process would present further processes and data requirements. Therefore, it would be necessary to define the "Recovery BOMs" (RBOMs). These RBOMs are not conventional BOM but must have a different structure and data model. Besides, RBOMs must offer the possibility of having several versions that correspond to the different alternative recovery options, which can cover distinct degrees of the disassembly process, quality standards, disassembly times and the performance of spare parts.

Our example includes a third requirement [44] because, evidently, scheduling must bear in mind that some components are to be supplied from returned refrigerators. Therefore, the returned refrigerators, the recovery rates of each component, repair times, disassembly, etc., must be included in the scheduling process to adequately schedule materials and operations.

Let's assume that four refrigerators need to be produced, and the inventory has 0 units of component Compressor, but there are four returned refrigerators in the inventory. As further information let's assume that the recovery rate of Compressors is 50\%. According to all this information, scheduling should indicate that it is necessary to purchase or produce two Compressors to manufacture four refrigerators because two units can be obtained from the returned refrigerators in stock (evidently, the returned refrigerators must be registered and identified in ERP as refrigerators to be disassembled). The available and necessary space data need to be considered to not only disassemble the components, but to also assemble the new refrigerators.

\subsection{Calculating Forecasts}

Calculating forecasts in RL is more complex than in DL because more uncertainty exists in RL [34]. Some general trends are observed that can be used. One of them is that the flows in RL tend to follow, albeit with some delay, direct flow trends. For example, the direct flow caused by Christmas sales is followed immediately by a proportional increase in returned products. So, when a large volume of sales of a given product is expected, these sales are also expected to come before a large volume of product is returned.

If remanufacturing also exists, as in the mentioned refrigerators example, forecasts are necessary not only given the possible recovery of cores, but also based on the availability and state of the components to be disassembled and reused.

All this means that forecasting the demand, calculated according to sales themselves, return periods and the specific return rate of each product, is necessary. The company's scheduling should be achieved by including this product returns forecast.

In the case of waste management, is important.

\subsection{Costs Management}

RL costs are not necessarily the same as DL costs, and the best practices for DL are not necessarily the best for RL. A paper presented the main RL costs and compare them to DL [39]. Most of these costs differ as regards importance and magnitude, but do not entail new requirements in ERP. Only repair, reassembly, and particularly disassembly and remanufacturing, costs involve making a necessary change to IS. These processes imply a need to develop a suitable system to manage RBOMs. Disassembly involves managing different costs because one same work and its associated cost must be distributed among the various components obtained in the same disassembly or recovery order.

Following the example of the recovered refrigerators [37] let's assume that one refrigerator arrives at the company to be reused. Its components are disassembled, and several components are obtained according to its BOM, from which one unit of component $A$ and one of component $C$ can be obtained, but one unit of component $B$ and one of component $C$ are rejected. So, the costs of the whole process 
must be distributed between the obtained components A and C, and they must be deflected with the refrigerator that they are assembled into.

In this process, the use of ABSC concept integrated with ERP (and MES if exists) could be very helpful. This costing tool could enhance the business operating abilities of quality, cost, delivery, service, resources, and productivity in a modern smart factory that uses high-tech unmanned vehicles, advanced robots, various sensors, etc. [18].

\subsection{Transport Management}

One of the main differences between DL and RL is the number of points of origin and destination [40]. When considering that DL generally involves moving a product from one origin to many destinations, the reverse product movement is the exact opposite: Moving from many origins to one destination. This characteristic implies a substantial difference in transport management, thus both delivery routes and product collection routes need to be taken into account.

Basically, combining direct and reverse transport can imply considerable savings in transport because this allows transport costs to be optimized. In this way, a truck that delivers products to the distributor also picks up products to be delivered to the manufacturer on the same journey, which optimizes transport.

Quite often, especially for retail trade, reverse product transport is normally done due to the distributer's logistics which, for instance, collect pallets when they have been emptied. In such cases, the combination and optimization of direct and reverse transports would not be possible because they would depend on two different organizations that do not use the same resources.

In addition, in some cases of multinational networks, a decision-making process is needed to determining which equipment (or materials) could be exported to be recycled in other countries and which will be recycled domestically [45]. This process needs information about costs, distances, facilities, legal requirements and regulations.

\section{Development Requirements to Adapt ERP}

The analysis performed for specific RL requirements in different processes reveals the need to include adaptations in ERP because these systems only contemplate DL processes.

In the disassembly and remanufacturing process, suitable processes in ERP systems need to be developed to be able to:

1. Suitably register cores when they arrive by a return process of recovered products which identifies information such as the origin of cores, the state they arrive in, their destination, etc. It is important to be able to set up a workflow according to this information to automate the process as much as possible, and for ERP to be capable of "directing" the returned core to the corresponding process in each case;

2. Manage product disassembly and remanufacturing. To do so, the RBOM concept needs defining and developing in which different components are obtained from one core that have several destinations (reuse, disassembly, recycling, scrapping, etc.). Each component must be registered and can, in turn, be decomposed into subcomponents. Because of this, they must be dealt with in the same way as cores and must, thus, be registered properly, as mentioned in the previous point;

3. Manage the production installations and resources jointly for production, and also for disassembly and remanufacturing. For this purpose, information about disassembly and remanufacturing has to be maintained in the ERP, such as returned cores (or in the return forecast), the recovery rates of the different components, the production rates with disassembly times, the spaces and resources to be used, etc. All this must be taken into account for production scheduling to achieve suitable materials and space scheduling;

To calculate forecasts in relation to product recovery, it is necessary to develop in ERP the process that allows suitable available information to be able to forecast demand, but by considering the 
product return possibility and how to make the best use of these products, e.g., both the core and its disassembled components.

In the costs management process, a complete data model must be developed in ERP that can manage the costs of disassembling a product and remanufacturing, including the costs of disassembly operations, and other costs related to returned products (e.g., the cost of transporting a returned product, the cost of rejected components, or the administrative costs incurred from returning). At this point it is stressed that the traditional BOM costs scheme in ERP is done away with, where the sum of the component costs, plus the associated operations costs, comprise the cost of the end product. With disassembly costs, a single product (the core) gives way to several components after they have been disassembled. Therefore, the costs associated with the core must be divided among the components it gave way to. Thus, the hierarchical relation is inverse because the distribution of costs goes "from one to many" instead of the traditional cost related to BOM, which goes "from many to one".

Finally, it is necessary to also adapt for transport management in such a way that transport can be optimized by considering both direct transport (delivering to customer) and inverse transport (collecting products). While developing ERP, the possibility of optimizing both transport types either jointly or independently for each type must be left open. In this way, both collection and delivery routes can be optimized for those companies in which the two are managed completely separately (or even in companies in which one of the two routes is outsourced), or both can be optimized jointly for those companies in which the same resources are used in both transport types.

Table 1 summarizes the development requirements that appear from the different processes analyzed in the previous section.

Table 1. The adaptation that ERP needs for RL management. Source: the authors.

\begin{tabular}{lll}
\hline \multicolumn{1}{c|}{ Process } & \multicolumn{1}{c}{ Development Requirement } \\
\hline 1. Managing disassembly and remanufacturing & - & $\begin{array}{l}\text { Suitably registering cores, and related } \\
\text { components and processes } \\
\text { Devising RBOMs and related processes } \\
\text { Modifying the production planning and } \\
\text { scheduling process by including RBOMs }\end{array}$ \\
\hline 2. Making forecasts & - & $\begin{array}{l}\text { Including forecasts for returned products and } \\
\text { the recovery rates of RBOMs if disassembly } \\
\text { is involved }\end{array}$ \\
\hline 3. Managing costs & - & $\begin{array}{l}\text { Developing a costs system adapted to } \\
\text { disassembly that is, in turn, compatible with the } \\
\text { costs system of DL }\end{array}$ \\
\hline 4. Managing transport & - & $\begin{array}{l}\text { Developing a process to optimize transport for } \\
\text { both RL and DL that can be used both jointly } \\
\text { and separately }\end{array}$ \\
\hline
\end{tabular}

It is necessary to consider that ERP is an overall and integrated solution. So, it is not possible to develop solutions for certain requirements without considering their possible relation with the rest, otherwise some developments would interfere with others. Therefore, ERP developers must have an overview to suitably plan and prioritize how requirements are implemented.

The requirements herein defined are related to one another; for instance, the solution to the disassembly and remanufacturing management requirement must be based on managing RBOMs that is, in turn, necessary to schedule disassembly, managing cores and recovered components, and scheduling assembly and disassembly. 
This obviously has a direct relation with calculating forecasts through scheduling that, in turn, is related with transport management because it is necessary to replan it by jointly considering direct and inverse systems. Evidently, all these processes are related with costs management, which must be able to acquire information from them all, and to analyze their costs in order to make decisions that enhance their efficiency, which will allow product prices and their profitability to be outlined.

The most complex requirement to adapt from the ERP point of view might be managing RBOMs because this management must be completely integrated with the master production and scheduling management of ERP, these being complex processes that must be modified. This requirement also strongly influences costs management. Thus, without forgetting that ERP adaptation must be made from an overview of all the requirements, it should start by developing RBOMs and integrating them into the master scheduling process and costs management.

Figure 2 presents an objects model that acts as the initial reference used to develop disassembly and remanufacturing requirements. This model represents the classes needed to develop the RBOM management process in relation to product recovery and the input of cores. This model can be used as a reference to develop the corresponding data model and to integrate it into a given ERP.

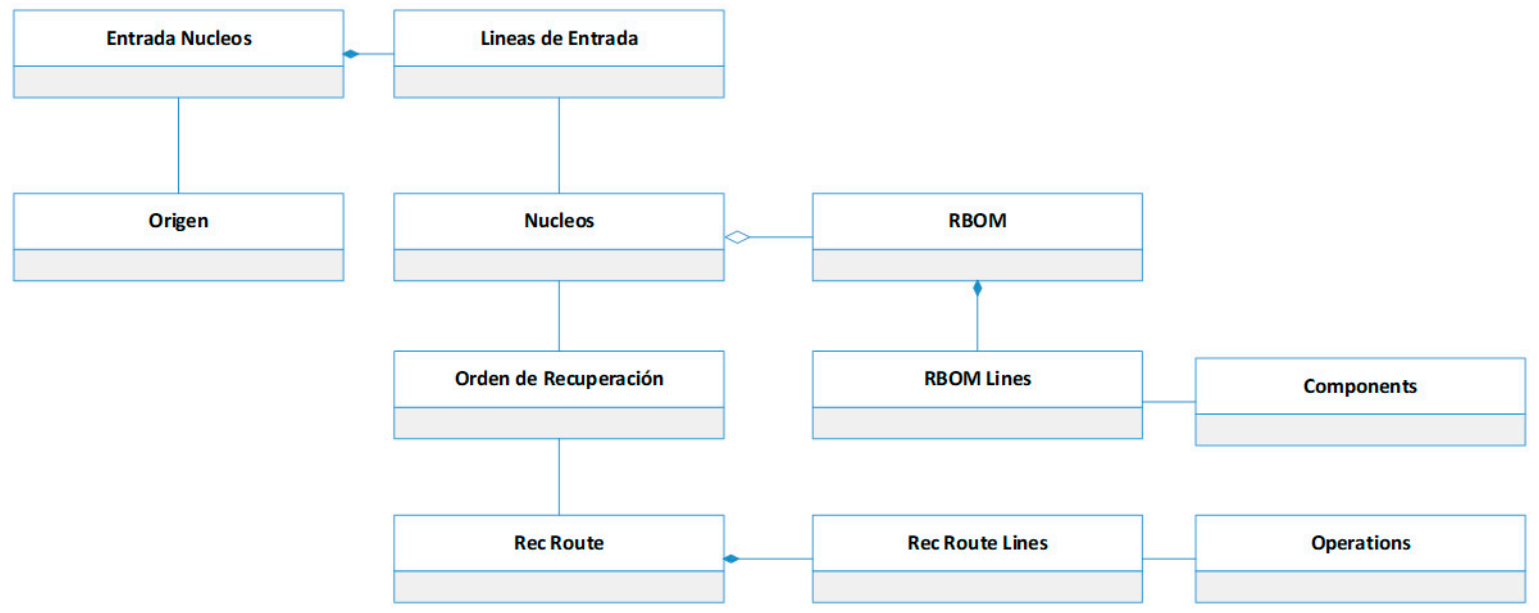

Figure 2. Objects model to develop disassembly and remanufacturing requirements.

In this model, the classes described in Table 2 are found:

By inputting this simplified objects models into a database, we obtain the following Organization-Relation diagram (Figure 3).

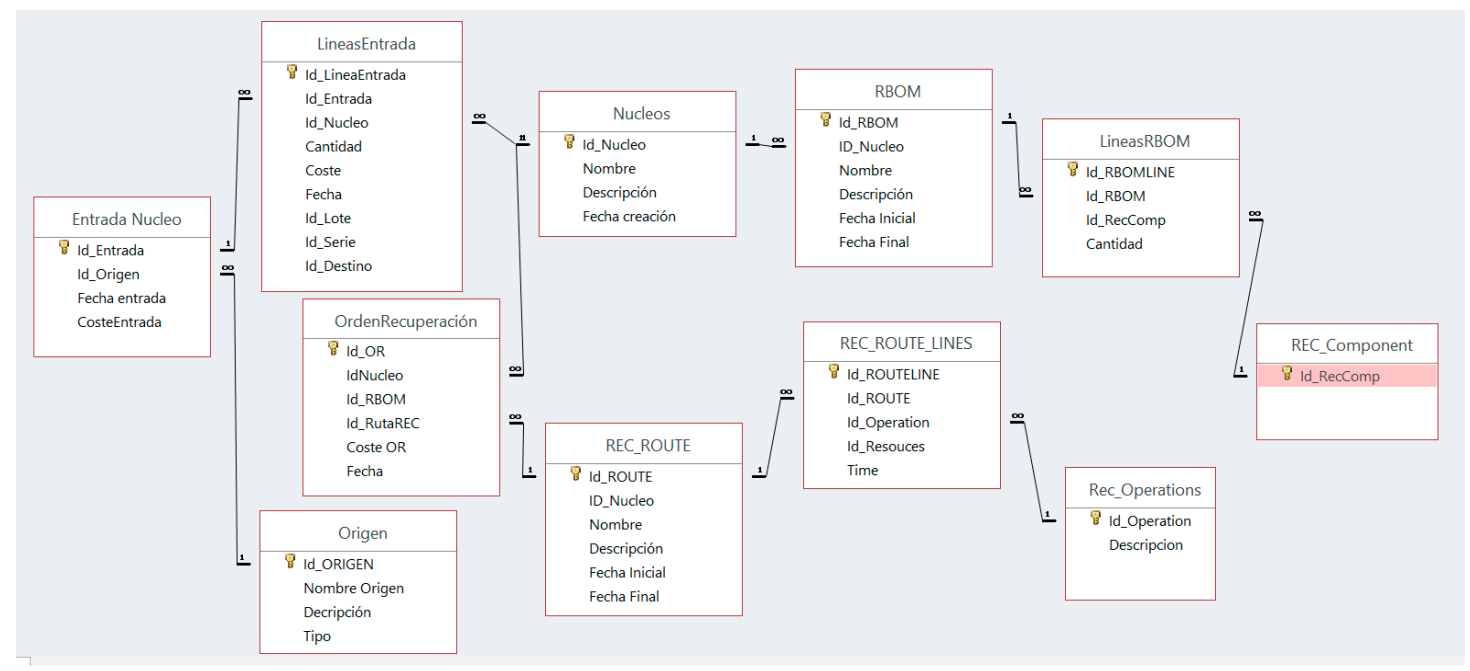

Figure 3. Data model for developing requirements. 
This data model allows tables to be produced with the information needed in ERP. We must also consider that it is necessary to schedule additional methods to calculate the cost and updating the aforementioned stocks.

Of course, this data model includes tables that can be included in or combined with the tables in the ERP system. For instance, the table "Rec_Components" will be included in the table "Articles" of the ERP system. Depending on the ERP system's functionality in which it is developed, "Rec_Operations" could be included in the table of the system's Production operations, and "REC_ROUTE_LINES" should be included with the Production resources table. This is quite particular in each given case, and also of the characteristic functionality and nomenclature of each ERP in which recovered products management is to be developed.

Table 2. Description of the classes to develop disassembly and remanufacturing requirements.

\begin{tabular}{|c|c|}
\hline Class & Description of the Class \\
\hline Origin & $\begin{array}{l}\text { The origin class refers to the origin of the inputted cores. They might come } \\
\text { from different sources and for various reasons, which may vary to a great } \\
\text { extent according to each company's processes. }\end{array}$ \\
\hline Inputting cores & $\begin{array}{l}\text { This class represents the main register of inputted cores. It comprises "Input } \\
\text { lines" and obviously has a cost that will depend on the total costs of the } \\
\text { lines and the specific delivery data by taking origin into account. }\end{array}$ \\
\hline Input lines & $\begin{array}{l}\text { They are each input of the different cores that may be in a delivery. They } \\
\text { update the existing stock of cores according to received quantities and } \\
\text { identify the state of each received core. They must calculate the input cost of } \\
\text { each line to include it later in the costs analysis. According to its state, each } \\
\text { core will have a destination (reuse, disassembly, etc.). }\end{array}$ \\
\hline Cores & They are inwardly received products that can be reused, recycled, etc. \\
\hline Order of recovery & $\begin{array}{l}\text { It represents the order of work, similarly to a "Production order", but unlike } \\
\text { these, it must transform a core into different components by considering } \\
\text { that the costs of obtaining each component will be proportionally } \\
\text { distributed to the work done to obtain them by considering the inputted } \\
\text { core cost, among other things. }\end{array}$ \\
\hline RBOM & $\begin{array}{l}\text { It is the "Reverse Bill of Materials", the bill of materials that will transform } \\
\text { each core into different components "explosively". As each core can be } \\
\text { processed in various ways and different components can be recovered in } \\
\text { each case, distinct RBOMs will be associated with the core. }\end{array}$ \\
\hline RBOM Lines & $\begin{array}{l}\text { Each RBOM line, where the components recovered from the core are } \\
\text { included, along with their quantities, states, destinations and, evidently, the } \\
\text { costs to obtain them. }\end{array}$ \\
\hline Components & $\begin{array}{l}\text { They are the components, products or "items" that are recovered after } \\
\text { performing the disassembly operations. }\end{array}$ \\
\hline Rec Route & It represents the Recovery Route that the core must cover. \\
\hline Rec Route Lines & $\begin{array}{l}\text { All the Rec. Route lines that will have an associated operation with the } \\
\text { resources needed to carry it out, as well as the times this is done in. } \\
\text { Obviously, this includes the work costs to charge them to the obtained } \\
\text { component/s. }\end{array}$ \\
\hline Operations & The possible operations to be carried out to recover products. \\
\hline
\end{tabular}

\section{Discussion and Conclusions}

The particular characteristics of RL processes generate a series of specific requirements in ERP because ERP currently adapts to DL processes, but not to RL processes. This article presents the implications that RL management has in ERP to provide developers of such systems with an overview of the requirements that RL management entails. 
After conducting the study, it was possible to verify that a requirement for ERP systems that adapts to the specific requirements presented in RL indeed exists, as herein described. These requirements derive from the peculiarity of RL in disassembly and remanufacturing processes, and when calculating forecasts, managing costs and scheduling transport. These processes have been identified, their particular requirements have been analyzed, and a data model for their management in an ERP has been proposed.

Therefore, the main objective of this article has been achieved. The specific requirements that an IS must meet to manage RL have been stablished, and a data model for the development of solutions to the requirements identified in an ERP system has been proposed.

As a conclusion, it must be said that developing these requirements must be dealt with from a global perspective as they all must interact. However, managing RBOMs, disassembly and remanufacturing are more complex processes with which most of the processes defined in the requirements are related. Thus, a development to adapt ERP to RL should start by dealing with the corresponding requirement to RBOMs by always considering the relations of this process with other requirements, especially with costs management. This is one of the main conclusions of the work, and a very valuable contribution for the practice. So far, no research work has identified and analyzed the specific problems that RBOMs generate, and their involvement in ERP systems. Moreover, no studies have proposed a data model for the RL management to be implemented in an integrated way in ERP systems. This data model proposed can be used by researchers and developers as a reference to develop particular solutions in concrete ERP.

On the other hand, the analysis of the specific RL processes and the existing problem for their management in an ERP system represents the main contribution to theory. The literature allowed us to conclude that an information system to manage RL properly is not yet available, although highly relevant. Some studies have remarked the need of technologies, but none of them have explored the particular situation of the ERP systems in the management of the RL processes. It must be said that the research carried out has limitations. The data model has not yet been implemented in an ERP and a real case. The processes have been identified and defined, as well as the associated requirements. However, they have not been developed to an exhaustive level of detail. For example, considering all the different legal requirements existing in different countries for the recycling management. Besides that, the data model is a generic one, that must be particularized for the specific development in concrete ERP systems and sectors.

Consequently, future research lines include looking at the analysis of each process herein described in-depth to propose specific solutions for each requirement they give way to, and at the tools used to optimize their management. For instance, mathematical models that help calculate forecasts or data models to manage disassembly and remanufacturing costs, maybe integrating ABSC. Developing a case study is also a future research line.

As indicated earlier, developing RBOMs is the most complex requirement and which has the most relations to all the other processes to be managed by ERP. Therefore, following this work, it is necessary to define and develop the RBOM concept and its management in ERP as an immediate research line before conducting any other research in this field. Finally, it would be necessary to implement into specific ERP the requirements defined for RL in the present work.

Author Contributions: Conceptualization, R.O.-B.; methodology, R.O.-B. and H.G.-G.; software, R.O.-B. and P.V.; validation, R.O.-B., H.G.-G., V.G.-N. and P.V.; investigation, R.O.-B., H.G.-G. and V.G.-N.; writing-original draft preparation, R.O.-B.; writing-review and editing, R.O.-B., H.G.-G., V.G.-N. and P.V.; visualization, R.O.-B., H.G.-G., V.G.-N. and P.V.; supervision, R.O.-B. and H.G.-G.

Funding: This research received no external funding.

Acknowledgments: The authors thank the anonymous reviewers for their constructive criticism, and the Interfaces editorial staff for its assistance, which helped us greatly improve the presentation of this article.

Conflicts of Interest: The authors declare no conflict of interest. 


\section{References}

1. Pinheiro, E.; de Francisco, A.C.; Moro Piekarski, C.; Taveira de Souza, J. How to identify opportunities for improvement in the use of reverse logistics in clothing industries? A case study in a Brazilian cluster. J. Clean. Prod. 2019, 210, 612-619. [CrossRef]

2. Narayana, S.A.; Pati, R.K.; Padhi, S. Market dynamics and reverse logistics for sustainability in the Indian Pharmaceuticals industry. J. Clean. Prod. 2019, 208, 968-987. [CrossRef]

3. Meyer, A.; Niemann, W.; Mackenzie, J.; Lombaard, J. Drivers and barriers of reverse logistics practices: A study of large grocery retailers in South Africa. J. Transp. Supply Chain Manag. 2017, 11, 1-16. [CrossRef]

4. Waqas, M.; Dong, Q.L.; Ahmad, N.; Zhu, Y.; Nadeem, M. Critical Barriers to Implementation of Reverse Logistics in the Manufacturing Industry: A Case Study of a Developing Country. Sustainability 2018, 10, 4202. [CrossRef]

5. Arango, M.D.; Gil, H.; Oltra-Badenes, R. Evolutions and Trends of Information Systems for Business Management: The M-Business. A Review. Dyna 2010, 77, 110-125.

6. Pohludka, M.; Stverkova, H.; Slusarczyk, B. Implementation and Unification of the ERP System in a Global Company as a Strategic Decision for Sustainable Entrepreneurship. Sustainability 2018, 10, 2916. [CrossRef]

7. El Hamdi, S.; Abouabdellah, A.; Oudani, M. Disposition of Moroccan SME Manufacturers to Industry 4.0 with the Implementation of ERP as a First Step. In Proceedings of the 2018 Sixth International Conference on Enterprise Systems (ES), Limassol, Cyprus, 8-9 October 2018; pp. 116-122.

8. Hack, S.; Berg, C. The Potential of IT for Corporate Sustainability. Sustainability 2014, 6, 4163-4180. [CrossRef]

9. Hernández-Sampieri, R.; Mendoza, C.P. Metodología de la Investigación: Las Rutas Cuantitativa, Cualitativa y Mixta; McGraw-Hill/Interamericana: Lomas de Santa Fe, Mexico, 2018; ISBN 9781456260965.

10. Hevner, A.R.; March, S.T.; Park, J.; Ram, S. Design science in information systems research. MIS $Q$ 2004, 28, 75-105. [CrossRef]

11. Sarkis, J.; Helms, M.M.; Hervani, A.A. Reverse logistics and social sustainability. Corp. Soc. Responsib. Environ. Manag. 2010, 17, 337-354. [CrossRef]

12. Stindt, D.; Nuss, C. Transdisciplinary Research in Sustainable Operations an Application to Closed-Loop Supply Chains. Bus. Strategy Environ. 2013, 22, 245-268. [CrossRef]

13. Rizzi, F.; Bartolozzi, I.; Borghini, A.; Frey, M. Environmental Management of End-of-Life Products: Nine Factors of Sustainability in Collaborative Networks. Bus. Strategy Environ. 2013, 22, 561-572. [CrossRef]

14. Searcy, C. Measuring Enterprise Sustainability. Bus. Strategy Environ. 2016, 25, 120-133. [CrossRef]

15. Chiarini, A. Strategies for Developing an Environmentally Sustainable Supply Chain: Differences Between Manufacturing and Service Sectors. Bus. Strategy Environ. 2014, 23, 493-504. [CrossRef]

16. Dos Santos, R.F. Integrated Model for Reverse Logistics Management of Electronic Products and Components. Proced. Comput. Sci. 2015, 55, 575-585. [CrossRef]

17. Wichaisri, S. Trends and Future Directions in Sustainable Development. Sustain. Dev. 2018, 26, 1-17. [CrossRef]

18. Tsai, W.H.; Lan, S.H.; Huang, C.T. Activity-Based Standard Costing Product-Mix Decision in the Future Digital Era: Green Recycling Steel-Scrap Material for Steel Industry. Sustainability 2019, 11, 899. [CrossRef]

19. Mahadevan, K. Collaboration in reverse: A conceptual framework for reverse logistics operations. Int. J. Produc. Perform. Manag. 2019, 68, 482-550. [CrossRef]

20. Kodhelaj, I.; Chituc, C.M.; Beunders, E.; Janssen, D. Designing and deploying a business process for product recovery and repair at a servicing organization: A case study and framework proposal. Comput. Ind. 2019, 105, 80-98. [CrossRef]

21. Rogers, D.S.; Tibben-Lembke, R.S. Going Backwards: Reverse Logistics Trends and Practices; RLEC Press: Pittsburgh, PA, USA, 1999.

22. Oltra-Badenes, R.; Gil-Gomez, H.; Merigo, J.M.; Palacios-Marques, D. Methodology and model-based DSS to managing the reallocation of inventory to orders in LHP situations. Application to the ceramics sector. PLoS ONE 2019, 14, e0219433. [CrossRef]

23. Jakupović, A.; Pavlic, M.; Poscic, P. Business sectors and ERP solutions. In Proceedings of the ITI 2010 32nd International Conference on Information Technology Interfaces, Cavtat, Croatia, 21-24 June 2010; pp. 477-482.

24. Oltra-Badenes, R.; Gil-Gomez, H.; y Guerola-Navarro, V. Metodología para la selección de sistemas ERP para pymes. 3C Empresa Investig. Pensam. Crítico 2018, 7, 10-33. [CrossRef] 
25. Ferran, C.; Salim, R. Enterprise Resource Planning for Global Economies: Managerial Issues and Challenges; NetLibrary, Inc Premier Reference Source, Idea Group Inc (IGI): Hershey, PA, USA, 2008.

26. Gunasekaran, A. Global Implications of Modern Enterprise Information Systems Technologies and Applications; Information Science Reference (an Imprint of IGI Global): Hershey, PA, USA, 2009.

27. McGaughey, R.E.; Gunasekaran, A. Enterprise Resource Planning (ERP): Past, Present and Future. In Selected Readings on Strategic Information Systems; Information Science Reference (an Imprint of IGI Global): Hershey, PA, USA, 2009; pp. 359-371.

28. Oltra, R.F.; Gil, H.; Bellver, R. Factores diferenciales entre los ERP de software libre (FSw ERP) y los ERP propietarios. Dir. Organ. 2008, 44, 64-73.

29. Ilankoon, I.M.S.K.; Ghorbani, Y.; Nan Chong, M.; Herath, G.; Moyo, T.; Petersen, T. E-waste in the international context-A review of trade flows, regulations, hazards, waste management strategies and technologies for value recovery. Waste Manag. 2018, 82, 258-275. [CrossRef]

30. Fiore, S.; Ibanescu, D.; Teodosiu, C.; Ronco, A. Improving waste electric and electronic equipment management at full-scale by using material flow analysis and life cycle assessment. Sci. Total Environ. 2019, 659, 928-939. [CrossRef]

31. Ikhlayel, M. An integrated approach to establish e-waste management systems for developing countries. J. Clean. Prod. 2018, 170, 119-130. [CrossRef]

32. Sommerville, I. Software Engineering, 9th ed.; International, Ed.; Pearson Cop.: Boston, MA, USA; London, UK, 2015; ISBN 9780133943030.

33. Malhotra, N.; Birks, D. Marketing Research: An Applied Approach, 5th ed.; Financial Times/Prentice Hall on Imprint of Pearson Education: Harlow, UK, 2017; ISBN 9781292103129.

34. Uriarte-Miranda, M.L.; Caballero-Morales, S.O.; Martinez-Flores, J.L.; Cano-Olivos, P.; Akulova, A.A. Reverse Logistic Strategy for the Management of Tire Waste in Mexico and Russia: Review and Conceptual Model. Sustainability 2018, 10, 3398. [CrossRef]

35. Isernia, R.; Passaro, R.; Quinto, I.; Thomas, A. The Reverse Supply Chain of the E-Waste Management Processes in a Circular Economy Framework: Evidence from Italy. Sustainability 2019, 11, 2430. [CrossRef]

36. Thierry, M.C.; Salomon, M.; Van Nunen, J.; Van Wassenhove, L. Strategic issues in product recover y management. Calif. Manag. Rev. 1995, 37, 114-135. [CrossRef]

37. John, S.T.; Sridharan, R.; Ram Kumar, P.N.; Krishnamoorthy, M. Multi-period reverse logistics network design for used refrigerators. Appl. Math. Model. 2018, 54, 311-331. [CrossRef]

38. Ardente, F.; Talens Peiró, L.; Mathieux, F.; Polverini, D. Accounting for the environmental benefits of remanufactured products: Method and application. J. Clean. Prod. 2018, 198, 1545-1558. [CrossRef]

39. Tibben-Lembke, R.S.; Rogers, D.S. Differences between forward and reverse logistics in a retail environment. Supply Chain Manag. Int. J. 2002, 7, 271-282. [CrossRef]

40. Fleischmann, M.; Bloemhof-Ruwaard, J.M.; Dekker, R.; van der Laan, E.; Van Nunen, J.A.E.E.; Van Wassenhove, L.N. Quantitative models for reverse logistics: A review. Eur. J. Oper. Res. 1997, 103, 1-17. [CrossRef]

41. Pokharel, S.; Mutha, A. Perspectives in reverse logistics: A. review. Resour. Conserv. Recycl. 2009, 53, $175-182$. [CrossRef]

42. Park, K.O. The Relationship between BPR Strategy and Change Management for the Sustainable Implementation of ERP: An Information Orientation Perspective. Sustainability 2018, 10, 3080. [CrossRef]

43. Fink, L.; Markovich, S. Generic verticalization strategies in enterprise system markets: An exploratory framework. J. Inf. Technol. 2008, 23, 281-296. [CrossRef]

44. Kokkinaki, A.I.; Zuidwik, R.; Van Nunen, J.; Dekker, R. ICT Enabling Reverse Logistics. In Reverse Logistics: Quantitative Models for Closed-Loop Supply Chains; Springer: Berlin/Heidelberg, Germany, 2004.

45. Dias, P.; Moura, A.; Huda, N. Ensuring best E-waste recycling practices in developed countries: An Australian example. J. Clean. Prod. 2019, 209, 846-854. [CrossRef]

(C) 2019 by the authors. Licensee MDPI, Basel, Switzerland. This article is an open access article distributed under the terms and conditions of the Creative Commons Attribution (CC BY) license (http://creativecommons.org/licenses/by/4.0/). 